\title{
3D Printing, Policing and Crime
}

\section{Angela Daly, ${ }^{1}$ Monique Mann, ${ }^{2}$ Peter Squires ${ }^{3}$ and Reece Walters ${ }^{4}$}

\section{Abstract}

This article examines the implications of advanced manufacturing technology, more commonly known as three dimensional (3D) printing, for policing and crime, notably the dissemination of digital design files and the use of 3D printers to produce illicit firearms. The application and rapid evolution of 3D printing technology has created new challenges for law and regulation, and represents an interesting security paradox, albeit one which until now has received scant attention in the criminological or policing literature. On the one hand, 3D printing denotes a significant shift in the creation and use of objects, ranging from food to body parts, and more controversially, weaponry (Fleschner McMullen 2014). On the other, the use of this technology to create items such as firearms and weapons signifies a potential safety, security, and legal challenge (Blackman 2013). We explore the emergence of 3D printing and its use to create firearms along with the theoretical challenges to legal design and enforcement presented by this decentralised technology. We also present some empirical data on instances of 3D printed firearms and firearm parts being detected internationally, and some jurisdictions' legal and policy responses. We conclude by considering that any regulation of 3D printed firearms must be based on a robust evidence base and take proper account of citizens' rights, but also that any national regulation will be in tension with the transnational and decentralised nature of the technology.

\section{Keywords}

3D printing technology, firearms, legal decentralisation, cybercrime, darkweb, law enforcement

\footnotetext{
${ }^{1}$ Assistant Professor, Chinese University of Hong Kong Faculty of Law; Adjunct Senior Research Fellow, Queensland University of Technology Faculty of Law. We acknowledge the support of QUT Faculty of Law Crime and Justice Research Centre and the research assistance of Harley Williamson in conducting this research.

${ }^{2}$ Vice Chancellor's Research Fellow, Queensland University of Technology Faculty of Law.

${ }^{3}$ Professor, University of Brighton School of Applied Social Science.

${ }^{4}$ Professor, Queensland University of Technology Faculty of Law.
} 


\section{Introduction}

3D printing, formally known as 'additive manufacturing', is the process of creating a threedimensional object via the layering of different materials including metals, paper and chocolate but most commonly (thermo) plastics (especially in cheaper machines), following the directions of an electronic Computer Aided Design (CAD) file. The conventional ink-based printer produces two-dimensional images, whereas $3 \mathrm{D}$ printing is capable of mass production in what many refer to as a manufacturing revolution (Lipson and Kurman, 2013). A key and innovative feature of additive manufacturing in the 3D printing process is its simplicity (Lewis, 2014). 3D printers are all-in-one machines that do not require system modifications on new designs; simplify the creation of complex structures; produce much less waste; and negate the need for additional tools (McCutcheon 2014; Meyer 2013).

This article examines the interface between 3D technologies and the complexities confronting contemporary, and transnational, policing. Specifically, we focus our argument on the increasingly rapid and largely unregulated emergence of 3D printing, with an emphasis on firearms. We present a series of instances that we have identified from media reports where 3D printed firearms or firearm parts have been located and investigated by police. identified and overviewed. From here, we also review the legal and enforcement models implemented to address 3D printing technology to date in different jurisdictions. This article concludes by outlining the challenges that these emerging digital disruptions present for law enforcement, civil liberties and progressive democracy.

Overall, we argue that a technologically determinist approach should not be taken regarding 3D printing and its possible use in crime. Other elements such as culture and (legal) geography, along with technological useability and socio-legal norms, seem to have some degree of influence on 3D printing's potential and actual use in general, and seemingly also for criminal purposes. We encourage law enforcement authorities to take a measured, evidence-based approach to addressing risks and threats from 3D printing, in order to avoid 'moral panics' around the technology which can be used - and mainly are used - for many socially beneficial purposes.

\section{Development of 3D printing Technology}

3D printing has been in existence since the 1980 s, but only in the last decade has it emerged into the mainstream, due to a combination of factors including the expiry of key patents and the lowering in price of $3 \mathrm{D}$ printers. In this time, $3 \mathrm{D}$ printing has enabled users to print a range of intricate and unique preassembled objects, including medical devices, instruments, edible structures, artistic items, and weapons (Fleschner McMullen 2014). 3D printers print objects by either scanning existing physical objects using laser scanners, or through Computer Aided Design (CAD) files (Harris Brean 2013; Meyer 2013), which 
can be readily downloaded, shared and exchanged on online file sharing sites. It is this digital / online dissemination that presents a series of challenges for transnational policing and security.

While plastic 3D printers can be purchased for well under US\$1000 (Rayna and Striukova 2016), metal printers are more expensive, yet they are becoming more accessible as technology advances. Indeed, very basic 3D metal printers seem to be available online now for under US $\$ 500$, albeit with poor functionality.

Consumers are also able to bypass purchasing 3D printers and can submit designs for manufacturing through 3D printing companies, which either have 'real-world' shopfronts or which function as e-commerce services (Rayna and Striukova 2016). This means 3D printing signals a potential shift in production from large manufacturers to individual consumers and smaller entities. This presents a number of challenges, including the sharing of design files and production of dangerous items. However, 3D printing is not only a threat: it has many socially desirable applications. 3D printing is also beginning to be used by police agencies for policing and security purposes, such as in crime scene evidence, to replicate body parts, and for criminal investigations (eg Baier et al 2018; Butler O’Neal 2015; Leung 2017).

In terms of potentially criminal uses of 3D printing, the most prominent and concerning threat has emerged in the form of 3D printed firearms and other weaponry (i.e. 'knuckle dusters'), one of the main focuses of this article. However, there are other potential criminal uses of the technology, especially in the form of intellectual property (IP) crime. The risks 3D printing presents for IP rights have been a prominent topic of legal discussion (see eg Bradshaw et al 2010; Daly 2016), but the issue has primarily been viewed from a private law, rather than criminal law, perspective. As yet, the large-scale IP infringement feared to ensue from 3D printing has not eventuated (Reeves and Mendis 2015; Mendis and Secchi 2015; Daly 2016), however there is some infringement occurring and future advances in technology may bring about the conditions for more infringement. Furthermore, 3D printed counterfeited objects, as with counterfeits manufactured by different means (see Forzley 2003), may also present safety risks to users due to being constructed in conditions, and with materials, which may be inadequate for purpose.

The fact that 3D printing can potentially be used for criminal purposes, and the process by which design files can be procured electronically either through creation or through online dissemination and sourcing, adds another 'dimension' to the concept of 'cybercrime' (which itself is a concept that some have argued is becoming outmoded - see e.g. Powell et al., 2018). This is the case both for design files comprising IP infringements and design files comprising other forms of illegal objects including firearms. While manifestations of cybercrime to date have resided in the virtual, 'extra-terrestrial' (see e.g. Lee, 2018) and indeed extra-territorial realm (see e.g. Mann \& Warren, 2018; Mann et al., 2018), the physical materiality of 3D printing and the potentially criminal outputs it can facilitate, coupled with its need for digital content which may be found on darkweb sites (and for some users, more publicly online via the Defense Distributed website) should be considered a part of the cybercrime discussion, but also leading to potentially more dangerous outcomes if 3D printed firearms proliferate. This also presents a series of additional challenges for criminalisation and policing due to the trans-territoriality of the internet and 
information flows in combination with the jurisdictionally bound nature of the criminal law (see e.g. Mann \& Warren, 2018; Mann et al., 2018). This presents a series of new and complex challenges for transnational policing, legal harmonisation (given positive conflicts in rights, for example the right to keep and bear arms in the US, discussed further below), and international law-enforcement cooperation.

\section{3D Printing and Legal Decentralisation}

3D printing forms one contemporary technology which can be considered 'decentralised' in contrast to previous forms of centralised manufacturing in the Fordist era. Indeed, 3D printing is one of various technological developments over the last two decades, their accessibility to the average person (at least in the [over]developed economies of the Global North see e.g. Carrington et al., 2018) and their socioeconomic implementations have led to a decentralising effect on the nature of production and organisation. Prominent among these have been: the Internet (decentralised production \& dissemination of information); 3D printing (decentralised production of [complex] objects); solar panels (decentralised production of energy); and the blockchain/bitcoin (decentralised production of money and decentralised documentation).

The category of 'prosumer' i.e. empowered individuals who both produce, as well as consume (Tapscott 1997), has come to be used with regards to those engaging with these technological developments (Benkler 2000; Butenko 2016; Daly 2016; Jacobs 2016). However, these developments stand in stark contrast to current legal and regulatory systems, which have generally been designed in a more centralised era where production (in developed economies at least) has mainly taken place in mass form via the bureaucratic structures of the State and the Firm i.e. through Fordist forms of production. The term 'Post-Fordism' covers a larger scope than just these decentralised technologies, and indeed was coined before most of them emerged into the mainstream. However, the participation of decentralised technologies in the paradigm change from Fordism means that they can be conceptualised as forming part of the Post-Fordist political economy.

Some commentators such as Rifkin $(2010 ; 2014)$ argue that these technological developments and their decentralised design may have profound social and economic benefits by democratising access to goods and services for very low costs, and could bring about a 'collaborative commons' rather than capitalist political economy. However, decentralisation may also bring about less empowering, more dystopian (for some) scenarios: for example the emergence of the 3D printed gun was welcomed by white supremacist groups (Fordyce 2015). Indeed, there are various political imaginaries across a broad political spectrum of 3D printing's future (Stein 2017).

Decentralisation presents a theoretical, and possibly also practical challenge to the design and enforcement of various areas of law. In the case of 3D printing, it is intellectual property laws, product liability law, medical device regulation, and, of course, criminal laws concerning firearms (Daly 2016). There has been scant discussion in legal or criminological circles of the impact of Post-Fordist forms of production and economy on the law and its enforcement, with the exception of labour law and regulation of transnational corporations (see eg Tickell and Peck 1995; Inagami 1999; Gendron et al 2004; Legault 
and Bellemare 2008). Recognition of the effects of Postfordist changes in the organisation of production, distribution and labour are beginning to become recognised in other areas eg European private law (Comparato 2016).

However, 3D printing throws the mismatch between Postfordist, decentralised manufacture and existing legal regimes into stark relief. Broadly speaking, existing legal regimes have been designed on the assumptions of centralised production and dissemination of manufactured products, along an identifiable supply chain and to a passive end-consumer. While law and its enforcement is often playing catch-up to new technologies, as noted in the idea of 'regulatory disconnect' (Brownsword and Goodwin 2012), with decentralised technologies such as 3D printing this is a 'double disconnect' inasmuch as the technology may be 'ahead' of the law but it is also designed and deployed differently to previous manufacturing technologies due to its decentralisation - another point of 'disconnection'.

3D printing's decentralised nature presents at least a theoretical challenge to the design and enforcement of criminal laws prohibiting unlicensed use, possession, sale and manufacture of firearms, as will be seen in the next section. However, there is also an empirical question regarding the extent to which this challenge is being realised in practice and at present there is no systematic data on this issue. We will engage with both of these questions in the following sections.

\subsection{Printed Firearms - New Terrain in the Gun Control Debate}

3D printed guns have not emerged in a social, cultural or legal vacuum. Here we explore some of these contexts and how they have interacted in particular with the emergence of Defense Distributed's 'Liberator' gun.

\subsection{Virtual Firearms and Real Dangers}

The first 3D printable gun attracted a great deal of media and law enforcement attention in 2013 when the software blueprints (or digital design files) to produce a '3D printable handgun', named the Liberator, were released onto the Internet, by the Wisconsin based company, Defence Distributed. Aided by social media promotion and much news interest, the technology struck a number of popular chords, achieving some 100,000 plus digital downloads in the first 24-48 hours, before the US State Department's, Directorate of Defense Trade Controls (DDTC) encouraged its removal from the internet on grounds that it could be in violation of the Arms Export Control Act, as they interpreted it (Jacobs \& Haberman, 2017: 129).

Wilson subsequently appealed the initial DDTC ruling on First and Second Amendment grounds, that digital Internet files were a form of 'free speech' and (especially in the wake of the Heller and 
McDonald Supreme Court judgements) and the 'right to bear arms'. This gave rise to a flurry of law review articles commenting upon the issues at stake (see, inter alia: Jensen-Haxel, 2012; Cosans, 2013; Johnson, 2013; Blackman, 2014; Masero, 2014; Little, 2014; McMullen, 2014; McCutcheon, 2014). During June of 2018, the US Department of Justice, at the behest of the Trump Administration, accepted the conflation of First and Second Amendment rights and conceded the case. The digital files for 3D printing firearms were to be re-released on the internet on August $1^{\text {st }}, 2018$. At the $11^{\text {th }}$ hour, however, a judge from the US District Court blocked publication on grounds of the potential public safety risks associated with an influx of new unregulated firearms, pending a full hearing of the issues. The ruling was accompanied by a tweet from the President, 'Already spoke to NRA, doesn't seem to make much sense!' he wrote (Shear et al., 2018).

Commentators have been divided as to whether the technology represented a kind of 'viral freedom' coterminous with the Internet itself, or the very worst kind of 'globally indiscriminate' weapon dissemination. 3D printing technology and the culture of homemade, unregulated, guns it facilitates could make firearms available to anyone, including all the dangerous, irresponsible, incompetent, mentally ill or criminally inclined people that most Americans believe should be restricted (Greenberg, 2018). In a number of countries, including the UK and Australia, police agencies, downloaded, produced, constructed and test-fired a version of the gun. The UK National Ballistic Intelligence Service (NABIS) concluded that the 3D printed firearm was a viable lethal weapon, but only good for three to four shots (assuming one could source suitable ammunition) as the plastic components began to crack and distort with repeated firing, the 'gun' becoming liable to explode in the hand. Although in other tests around the world the performance and durability of the weapon was seen to depend upon the quality of plastic/resin used in the weapon construction (Walther, 2015). ${ }^{5}$ Within a year or so news broke of a 1911 model semiautomatic pistol, the components for which had all been produced by a metallic 3D printing process. The company which produced the weapon, Solid Concepts Inc., acknowledged that the weapon had required some 'gunsmithing and finishing' in order to construct the final functioning firearm, but that, in a test some 4,500 rounds had been fired without malfunction. The company claimed that a number of these weapons had been sold to the public, but that, at a price of $\$ 11,900$, they were not yet commercially viable (Jenzen-Jones, 2015).

The contrasting reactions to these new 'digital' firearms spoke volumes about different attitudes to firearms and freedoms, rooted in widely differing 'gun cultures', legal traditions and policing systems and what Squires has referred to as a range of diverse 'gun control regimes' (Squires 2014). The purpose of distinguishing such regimes is to understand the differing contexts in which various mechanisms of supply and demand, sustained by contrasting attitudes to weapons, patterns of enforcement, especially firearm licensing systems (including 'loopholes' in regulations) and the scale of existing gun ownership,

\footnotetext{
${ }^{5}$ By 2014 Wired was reporting the development of a firearm round designed specifically to be fired from 3D printed guns. This ammunition uses a thicker steel shell so that the shell-casing contains the explosion of the round's gunpowder rather than the the plastic barrel of the gun. The current drawback, making the process far from commercially viable is that each cartridge case has to be individually machined on a lathe. The process can take up to an hour, although the raw materials cost only 27 cents each. Once the shells are produced they can be fired, then repacked with new bullets, gunpowder and primer to be shot again (Greenberg, 2014).
} 
histories of relationships between firearm use and misuse, and criminal cultures and entrepreneurship, might significantly shape attitudes towards 3D firearms whilst also conspiring to incentivise covert and illicit 3D production. For example, Meyer (2015) has argued that, as a result of 3D printing technologies, 'the 3-D printing of SALW will further promote the illicit manufacture of arms by facilitating and democratizing the process of manufacture ... SALW are bound to become more accessible and widespread in countries where strict gun control is in place' (2015: 558, 571). In Japan and the UK, for instance, countries with strict gun control, initial reactions to 3D printing were firmly defensive, a man was arrested by Japanese police for illegally printing a gun' (Bunker, 2015) and, as we have seen, the UK police ballistics intelligence agency produced a copy of the weapon in order to assess the weapon for regulation purposes while various journalists 'tested' anti-trafficking security measures by attempting to smuggle a 3D printed firearm (Meyer, 2015).

Meyer also considered the case of Mexico where relatively few citizens unconnected to the police or military legally own firearms, yet illegal weapons, mostly sourced from the USA, proliferate amongst the drug cartels and their supporters. He concluded, 'in countries like Mexico ... it is likely 3D printed weapons will become more accessible to the common citizen not involved with the cartels or army, but, who nevertheless desire to have a weapon'. By contrast, 'it appears unlikely that the technology of 3D printing weapons will have much a of a destabilizing domestic effect within the United States due to the existing mature market for firearms and the ease with which those who would otherwise be prohibited from obtaining a firearm may acquire one cheaply and illicitly via "straw purchases"' (Meyer, 2015: 571). However implausible Mayer's suggestion that 3D printing might slow the rate of firearm trafficking southwards into Mexico, his observations regarding the regime level police and regulatory differences are worth taking seriously. He correctly anticipated the significant legal wrangling over gun ownership, freedom of speech and expression and Fourth Amendment rights regarding arbitrary search and seizure, trade in military components and copyright and intellectual property, which followed in the USA.

Australia, by contrast, had initially shared relatively liberal attitudes towards firearm ownership, but since the semi-automatic rifle buyback following the Port Arthur shooting in 1996, saw these tightly regulated. Given a number of recent cases reported in the media in Australia in which illegal 3D printing firerams have been unearthed (see Table 1) it appears that increasing restriction may have (for a while at least) made certain types of weapons harder to access, thereby galvanising police action on firearm security, whilst also incentivising the criminally inclined to seek firearms and weapon components by other means (Squires, 2014: 289-298; Bricknell, 2012). This might include illegal domestic production of firearms and the assembly of smuggled firearm components as well as the illegal weapon conversion and reactivation practices that take place in a number of relatively high control gun regimes (Squires, 2014: 65). We explore these Australian instances more below.

Such issues also raise another anomaly pertaining to illegal weapons which is that the basic mechanics of firearm design and functioning have not changed much over the past 200 years. The irony here is that sophisticated 3D printing using internet software has succeeded in producing a firearm that, in many respects, would not seem functionally out of place in 1850. Seldom can such cutting edge digital technologies have produced something so practically, socially and functionally obsolete. Furthermore, 
rather more than a tool-like functionality is involved when a man picks up a gun - there is a psychological tie, and typically emotional reaction; the gun has to both look good, feel good, embody ergonomic virtue and what is sometimes referred to as inherent 'pointability'. In the full sense of the word, firearms are 'consumed' rather than simply fired (Haag, 2016; Squires, 2019 forthcoming). As Jacobs and Haberman commented 'at least in the short term, 3D printed guns will not compete successfully with traditionally manufactured guns in terms of reliability, quality, and cost... most terrorism and gun crime will, for the foreseeable future, continue to be perpetrated with mass produced weapons' (Jacobs \& Haberman, 2017: 147).

The advent of 'modular' (and Lego type / looking in the case of 3DP printed firearms such as the Liberator) firearm components, however, poses further issues. Modular weapons are firearms constructed from several different interchangeable components allowing owners to partly 'customise' their guns with a number of additional or alternative features. Many popular - military specification but (in the USA) civilian marketed - 'assault weapons' are available in this 'modular' format, with detachable sound and flash suppressors, bipod stands, larger magazines, and a variety of different stocks. Concern arose in 2017 following the Las Vegas shooting where 57 people were killed, when it appeared that the shooter had modified a number of his assault weapons with a so-called 'bump-stock' attachment, effectively converting the weapon to full automatic fire. The idea the 3D printed and, at the time, legally available 'bump-stocks' might be widening a loophole in the National Firearms Act of 1934 which had sought to prohibit civilian ownership of machine guns ('gangster weapons') raised a number of alarms.

Further security issues arise in respect of modular firearms concerning the weapon frame, or lower receiver. In the case of the popular AR15 type assault rifles, the lower receiver contains the operational components of the firearm, including the trigger mechanism and the magazine, it is also where the weapon's serial number is stamped and the only part of a weapon regulated by law when an assault weapon is disassembled. Weapon security and supply side controls could be compromised if consumers might simply print out whatever components they need via a 3D printer (Jensen-Haxel, 2012). Assault rifles with 3D printed lower receivers without serial numbers have given rise to a concern with so-called 'ghost guns' in the USA (Van Brocklin, 2015). Defense Distributed have already released film of a functioning assault rifle with a 3D printed lower receiver (Farivar 2013a). The same clip of film, from 2013, appeared repeatedly on British television channels when the 3D firearm issue resurfaced in late July 2018 in anticipation of Defense Distributed's worldwide re-release of the digital printing files, scheduled for release on 1 August 2018 . Evidence has also emerged of unmarked and unregistered lower receivers for Glock handguns (not genuine Glock components) surfacing in criminal investigations in Los Angeles (Caron, 2017; Evans, 2018) and also being intercepted on weapons trafficking routes in Western Europe. 


\subsection{Ideology, Firearms control and security questions}

Walther explored the broader 'security implications' of the new 3D technologies in an article in 2015, distinguishing between the implications for national and international trade regulations, EU regulation of military technologies, and potential conflicts with the UN Arms Trade Treaty (signed by 122 states) and which entered force in December 2014 (Walther, 2015: 1439). It is clear that Cody Wilson, the US developer of the 3D firearm technology had an explicitly ideological motivation for developing and releasing the 3D digital firearm software - that is, the realisation of Second Amendment rights (Van Vugt, 2013). His choice of name for the 3D pistol, the Liberator, harking back to the single shot pistols dropped into occupied France for the resistance during the Nazi Occupation, and the title of his company, Defense Distributed, provides clues (Cadwalladr, 2014). Wilson was seeking to frustrate existing firearms regulation, especially the UN arms control agenda and the Arms Trade Treaty which many Americans have condemned as a threat to US values, freedoms and the Constitution (La Pierre, 2006).

Describing himself as a 'crypto-anarchist' he argued that freedom and equality demanded that everyone have the capacity to build and own a firearm, envisaging ' $3 \mathrm{D}$ printers in more and more homes' (McMullen, 2014) and 'democratised manufacturing' (Lindstrom 2014). In this respect, in seeking to 'globalise' Second Amendment rights he appeared to ally himself with some of the more militant firearm advocates of the NRA (Squires, 2018). Wilson and his colleagues were committed to dismantle what they considered to be 'the reactionary, control-oriented state government' by completely circumventing its control nexus through a hollowing out of the regulatory capacities of large bureaucratic institutions (Van Vugt, 2013), aiming at a decentralised production which would frustrate the design and enforcement of state law. There was undoubtedly something uniquely opportunist and controversial about the 3D printing of firearms, both in societies awash with civilian owned firearms as well as in those with very few, as some commentators have noted. ${ }^{6}$ By contrast, gun industry watchers have remarked that $3 \mathrm{D}$ printing is just 'a high-tech version of what's been going on in the margins of the gun industry for a long time - looking for clever ways to market firearms that evade federal restrictions' (Timothy Lytton, cited in Shear et al., 2018).

According to Jensen-Haxell, 3D printing marked the inevitable obsolescence of supply-side controls (licensing systems, ownership databases, and pre-distribution background checks) on firearms: '3D printers will render current firearm regulations obsolete', he argued (Jensen-Haxell, 2012). He claimed that with over three hundred million firearms already in civilian possession in the USA, the gun control ship was already foundering; 3D printing was simply the final blow. Unenforceable blanket prohibition of 3D printing would not offer a solution and arguments regarding the need to regulate this new technology and its various products before it 'outpaced the law' (Cosans, 2014; Jensen-Haxell, 2012), such as McMullen's proposal for a 'Digital Gun Act' (2014), were said to be narrow and outdated.

\footnotetext{
${ }^{6}$ Other commentators, however, remarked that any regulative focus should concentrate upon the gun itself rather than the technology to produce it. After all, 'all technology is connected to all conduct, including crime, that technology may facilitate'). Criminalising new technology simply because it might be misused, could be considered excessive: 'the technology of 3D printing is a distraction, albeit a relevant and fascinating one, from the question of whether and how best to regulate guns generally... 3D printers don't kill people - guns do' (Thierer \& Marcus, 2016).
} 
So rather than trying to refloat gun control, Jensen-Haxell argued, $21^{\text {st }}$ century citizens needed to 'learn to swim' embracing firearm ownership as a contemporary way of life: '3D printing will set us free' he enthused.

This aspiration is broadly consistent with Wilson's overall transformative social and political mission. For while possession of a firearm, in and of itself, entailed some very important transformative and capacity enhancing features (empowerment, autonomy) for individuals (Squires, 2017), it was the internet dream of continuing 'permissionless innovation' - the transformation of political culture at large - that appealed, above all, to Wilson and Defense Distributed (Thierer \& Marcus, 2016: 840). Therefore, 3D printing was heralded as the dawn of a new - decentralised - industrial revolution, and the precursor of a fundamental transformation of the relationships between the individual and political 'authority' in the widest sense, due, as mentioned above, to its decentralised design. And here, of course, lay one of its core contradictions. The leadership of the NRA, perhaps representing firearm manufacturers rather more emphatically than libertarians and gun owners, seemed rather more enthusiastic about people buying firearms rather than printing them off the internet and building their own. ${ }^{7}$

\section{Legal and Enforcement Approaches to 3D printed firearms}

We have identified a number of instances of 3D printed firearms or firearm parts being discovered throughout the world and these are presented in Table 1. We used media reports to identify these instances, given police data is not publicly available, and it is not clear whether police are actually collecting data on such instances. Our approach has various limitations (as does all research derived from media reporting), but it provides at least an indication of some occasions in which 3D printed guns have been identified by police. While, as mentioned earlier, the 3D printed gun symbolises challenges to the design and enforcement of criminal laws, these reports suggest firstly that the use of 3D printing to create illicit firearms is not yet particularly widespread, and secondly that law enforcement agencies are detecting firearms and firearm parts made illicitly using 3D printing and thus exercising some level of control over the creation and use of these objects.

This is because many existing laws and offences regarding the unlicensed manufacture, creation and possession of firearms will extend to 3D printed firearms, although not necessarily the possession or distribution of the digital design files. However, the Australian jurisdiction of New South Wales was the first to introduce a specific offence of possessing or distributing firearms design files.

\footnotetext{
7 As Meyer had predicted, 'it is not difficult to foresee a strong conflict of interest between the fiduciary obligation of the gun manufacturing industry to share-holders and the promotion of the NRA's own mission statement to 'foster the Second Amendment rights of all law-abiding Americans' because of the strong financial ties between the NRA and the gun industry, and because of the strong financial stress that could result from the widespread distribution of 3-D printed weapons, one can reasonably conclude that the existing gun lobbying organizations will not come to the legislative aid of those working to expand the technology of 3-D printed weapons' (Meyer, 2015: 572).
} 
While the 3D printed gun for some has symbolised crypto-anarchist ideals circumventing legal prohibitions, legislatures and governments have attempted to respond to that threat through a range of legal approaches in various jurisdictions (Table 2). These approaches can be grouped into categories:

- Explicitly criminalising the manufacture of 3D printed firearms under existing laws;

- licensing or registration schemes for 3D printers and 3D printed firearms; and

- the introduction of new offences for the possession of design files for 3D printed firearms.

In addition to national legislation and policy initiatives, there are various international agreements related to restrictions on arms exports which may also encompass 3D printed firearms. The United Nations Arms Trade Treaty (ATT) covers the export of 3D printed weapons as light arms and firearm components but does not cover the dissemination or possession of 3D design files. The Wassenaar Agreement covers exports controls on 3D printed weapons and also blueprints for these weapons. In the European Union, the Council Common Position 2008/944/CFSP defining common rules governing control of exports of military technology and equipment would require that individuals obtain a relevant license to export 3D printed firearm designs.

As with an absence of robust and systematic evidence as regards to the occurrence of 3D printed firearms (or firearm parts) being discovered by police, at present there is no empirical data on how successful (or perhaps not) these different measures criminalising and attempting to restrict the creation and dissemination of 3D printed firearms and design files have been. Furthermore, there is no evidence on whether certain approaches eg creating new technology-specific offences as in the Australian jurisdiction of New South Wales have proved effective. Along with the lack of robust data on instances of the quantity of design files available online, the number and type of 3D printed guns being identified by law enforcement or used in the commission of crime, we do not have a clear and evidence-based picture at the moment both of how prevalent 3D printed guns are, and how successful or not legal and other policy measures are in deterring or detecting and punishing their creation and use. The instances of 3D printed guns we identify in Table 1 are from media reports, with the limitations of this noted above. This means that we do not have complete details about these instances including the context in which the guns or parts were found or the motivations supporting their production (although a consistent theme was also involvement in drug offences). That is, in some cases, particularly those in Australia, the 3D printed guns and parts were found when police were raiding premises for other purposes eg suspected organised crime involvement and/or drugs trafficking activities. This raises questions about the 'unknown unknowns' - ie whether, and to what extent, there are instances of 3D printed gun creation and dissemination that are not being detected and publicised. The true picture of the threat posed by 3D printed guns cannot be identified without further research, if indeed at all (given the 'dark 
figure' of crime). However, it seems that law enforcement agencies are able to exercise some measure of control over what Defense Distributed and its ilk view as an uncontrollable technology.

In addition to these forms of state-led regulation of 3D printed firearms, private regulation has also been used. One early example occurred When Defense Distributed was ordered by US authorities to remove Liberator gun files in 2013 and Mega's Kim Dotcom also directed his staff to remove public links to the files despite Mega being situated geographically outside the US (Ferenstein 2013; Daly 2016). More recently, in August 2018, Facebook announced that sharing instructions on how to print firearms through its services would breach its Community Guidelines, specifically its Regulated Goods Policy which concerns firearms (Jackson 2018). In addition, there have been calls for 'by-design' regulations to prevent $3 \mathrm{D}$ printers from printing firearms. An algorithm to detect and prevent the printing of 3D firearm CAD designs has been proposed (Farivar 2013b). This means 3D printing machines could be pre-loaded with a database of designs that could be matched to prints, which could prevent the printing of unauthorised files for firearms. In the absence of specific legal requirements to implement these measures, 3D printing machine manufacturers which do decide to restrict or forbid their products and services being used in ways which may facilitate the creation of, and access to, 3D printed guns engage in private regulation. Again, there is no data about how effective these measures are, which would be useful to inform law- and policy-making in this area.

Other possible measures which could be taken to limit access to 3D printed guns and design files might involve the 'hashing' of digital design files by police (or private companies such as Google) who can then trawl the Internet to identify and remove this material, as is currently common practice with child exploitation material. However, such actions may prove controversial given the transnational nature of the Internet as compared to the national-nature of police forces, particularly given that possession of 3D printed gun blueprints or the manufacture firearms is not a crime in all jurisdictions, and indeed in the US it is a right. This raises issues of online censorship and free speech.

\section{To Print or Not to Print - 3D Firearms, Freedom of Information and the Quest for Security}

Indeed, restricting 3D printing and uses on the basis of addressing the threat from 3D printed firearms may have both unintended consequences and may also conflict with users' rights. Restricting information including in the form of 3D printing design files may have a deleterious impact on freedom of expression, a 'fundamental human right underpinning all civil liberties' (UNESCO, 2018). The ability to express diverse opinions, whether verbally or digitally, and thus facilitate the free-flow of information in society is often considered the hallmark of a progressive and well-functioning democracy (Birkinshaw, 2006). Yet, historically speaking, the suppression of controversial and unorthodox views (that would ultimately be proven correct, reasonable and socially palatable) and the punishment of the respective 
authors on topics of science, religion, and technology has resulted in widespread injustices (Bakircioglu, 2008). However, societies have placed restrictions and responsibilities on free speech to prevent inciting hatred or violence (Gearty, 2007); or to prevent the exploitation of children. Even the US with its strong First Amendment protections does limit free expression.

The 3D printed firearms debates offers some interesting dilemmas regarding freedom of expression. On the one hand this is an exciting scientific breakthrough with immense potential to enhance social and environmental improvements, on the other hand, as is the case with guns and other explosive devices, it is a technology with the potential to kill innocent people and promote other forms of criminal activity. The law as a means to mitigate and regulate these tensions is often positioned to balance the argument around risks, responsibilities and rights. Yet, the extent to which law can effectively intervene to control 3D printing is debated given the aforementioned decentralised design 3D printing encompasses and the associated difficulties this presents, at least in theory, for legal design and enforcement.

The advent of the 3D printing is not alone with such debates about access to, and use of emerging technologies. The 'cyberworld' (or 'digital realm' already offers users access to information about the manufacture of synthetic diamonds, the cultivation of illicit drugs, techniques in uranium enrichment and many other knowledge bases that whilst having the potential to create black markets and social harm, also have utility within medicines, legitimate trade and energy markets. We do not advocate for the censorship of online knowledge, including in the form of 3D printing design files for firearms and other risky objects. It is the use of that knowledge, in the form of constructing the objects, that requires scrutiny, whether legal or otherwise.

Furthermore, this scrutiny needs to be evidence-based regarding the threat that $3 \mathrm{D}$ printed firearms actually present. While the decentralised nature of 3D printing does present serious theoretical challenges to legal design and enforcement, including of the criminal law, the emerging reality is much more complex. Aside from law enforcement agencies themselves using 3D printing for their own purposes (for example forensic reconstruction), they have detected the creation of 3D printed firearms on a number of occasions in countries such as Australia, Japan and the UK which all have much stricter regulation of firearms than the US. This would seem to dampen the disruption caused to law and law enforcement by 3D printing. However, more complete and systematic evidence is required, including the effectiveness of legal and policy responses to 3D printed guns, before we can understand what kind and extent of regulation is appropriate, also taking account of the countervailing interests in free expression and transnational information flows, particularly when one considers the many socially beneficial uses of 3D printing.

Finally, we acknowledge that formal laws are not the only constraint on the use of 3D printing, especially to create firearms. Geographical location, especially in the case of Australia's isolation, may make 3D printing more or less attractive as a means of producing illicit weapons, rather than using more conventional methods. Culture, including 'gun cultures', also has an influence on the social acceptance or not of 3D printed firearms. Accordingly, the question of the regulation of 3D printed guns should be neither legally determinist nor technologically determinist, and must account for these other factors and influences as well. 


\section{Conclusion}

3D printed firearms have shot into the mainstream consciousness as a development with the potential to be hugely disruptive to criminal and intellectual property laws and their enforcement, particularly in countries outside of the US with strict gun control laws. The law has responded to the emergence of 3D printed guns in various ways in various jurisdictions, police forces have detected $3 \mathrm{D}$ printed firearms and firearm parts and other actors have also engaged in private regulation of technology to stem the flow of information that can be converted into dangerous material. Other factors including culture and geography also seem to play a role in the prevalence of, and interest in, 3D printed firearms. Accordingly, neither a technologically or legally determinist approach should be taken to the risks presented for public safety by $3 \mathrm{D}$ printed guns - the emerging picture is much more complex.

However, these conclusions are tentative given the lack of robust data on instances of 3D printed firearms and effectiveness of measures to address them. It is imperative that an evidence base is developed to understand the actual and projected implications of 3D printing and crime, in order to design suitable legal and policing frameworks which do not overly interfere with citizens' rights and the socially beneficial aspects of 3D printing. Challenges also encompass regulating a transnational technology through national measures in terms of law or policing, or leaving regulatory measures to large transnational private actors such as 3D printing industry players. Differing legal, cultural, geographical environments also present conceptual challenges regarding designing appropriate measures for such a transnational technology, particularly when taking account of countervailing interests such as human rights to free expression and restrictions on that right which may differ between countries. Only a robust evidence base will provide proper insight into the extent to which these theoretical challenges are playing out in practice with 3D printed firearms.

Finally, cognisance should be made of other potentially criminal applications of 3D printing extending beyond firearms manufacturing. There is also the possibility of using 3D printing to facilitate IP infringement and counterfeiting which may also involve safety risks for consumers. While large scale IP infringement is not currently occurring (to our knowledge or in media reporting), this is another area which should be monitored by the relevant authorities and researchers alike. 


\section{REFERENCES}

Anderson, C. 2010. In the Next Industrial Revolution, Atoms Are the New Bits, WIRED. Available at: www.wired.com/magazine/2010/01/ff_newrevolution.

Baier, W., Warnett, J.M., Payne, M. and Williams, M.A. 2018. Introducing 3D printed models as demonstrative evidence at criminal trials. Journal of Forensic Sciences, 63(4), 1298-1302.

Bakirioglu, O. 2008. 'Freedom of Expression and Hate Speech', Tulsa Journal of Comparative and International Law. 16(1):1-51

Benker, Y. 2000. 'From Consumers to Users: Shifting the Deeper Structures of Regulations Towards Sustainable Commons and User Access' Federal Communications Law Journal, 52, 561-579.

Birkinshaw, P. 920060 'Freedom of Information and Openness:Fundamental Human Rights Commentary', Administrative Law Review, 58:177-218.

Blackman, J. 2013. The 1st Amendment, 2nd Amendment, and 3D printed guns. Tennessee Law Review, $81,479-539$.

Bradshaw, S., Bowyer, A. and Haufe, P. 2010. The Intellectual Property Implications of Low-Cost 3D Printing. SCRIPT-ED, 7(1): 5-31.

Bricknell, S. 2012. Firearm Trafficking and Serious and Organised Criminal Gangs. AIC Reports: Research and Public Policy Series, No. 116. Canberra: Australian Government.

Brownsword, R and Goodwin M. 2012. Law and the Technologies of the Twenty-First Century. Cambridge: Cambridge University Press.

Bunker, R. J. 2015. Home Made, Printed, and Remote Controlled Firearms - Terrorism and Insurgency Implications. TRENDS Research \& Advisory. Available at: http://trendsinstitution.org/homemadeprinted-and-remote-controlled-firearms-terrorism-and-insurgency-implications/.

Butenko, A. 2016. Sharing Energy: Dealing with Regulatory Disconnection in Dutch Energy Law. European Journal of Risk Regulation, Vol 7, Issue 1 701-716.

Butler O’Neal, B. 2015. 3D printed beer bottle is instrumental evidence in UK murder conviction. 3DPrint.com. Available at: https://3dprint.com/59380/3d-printed-evidence-for-trial/.

Cadwalladr, C. 2014. Meet Cody Wilson, creator of the 3d-gun, anarchist, libertarian. The Observer. Available at: http://www.theguardian.com/technology/2014/feb/10/cody-wilson-3d-gun-anarchist.

Caron, C. 2017. 'Ghost Guns,' Homemade and Untraceable, Face Growing Scrutiny. New York Times. Available at: https:/www.nytimes.com/2017/11/27/us/ghost-guns-gabby-giffords.html.

Carrington, K., Hogg, R., Scott, J. and Sozzo, M. (ed.). 2018. The Palgrave Handbook of Criminology and the Global South. Cham, Switzerland: Palgrave Macmillan. 
Chase, R.J. and LaPorte, G. 2017. The next generation of crime tools and challenges: $3 D$ printing. Washington DC: National Institute of Justice.

Comparato, G. 2016. 'Factors behind the transformations of private law' in Guido Comparato, Hans-W Micklitz and Yane Svetiev (eds), European regulatory private law - autonomy, competition and regulation in European private law, EUI Department of Law Working Paper 2016/06.

Cosans, J. 2014. Between Firearm Regulation and Information Censorship: Analyzing First Amendment Concerns Facing the World's First 3-D Printed Plastic Gun. Journal of Gender, Social Policy \& the Law, 22(4), 917-946.

Daly, A. 2016. Socio-Legal Aspects of the 3D Printing Revolution. Palgrave Macmillan.

Evans, C. 2018 Law enforcement struggling to combat unregulated, DIY "ghost guns". CBS News. Available at: https://www.cbsnews.com/news/law-enforcement-struggling-to-combat-unregulated-diyghost-guns/

Farivar, C. 2013a. "Download this gun": 3D-printed semi-automatic rifle fires 600 rounds. Ars Technica. Available at: http://arstechnica.com/tech-policy/2013/03/download-this-gun-3d-printed-semiautomaticfires-over-600-rounds/.

Farivar, C. (2013b). Worried about accidentally 3D printing a gun? New software will prevent it. Ars Technica. Available at: https://arstechnica.com/information-technology/2013/06/worriedabout-accidentally-3d-printing-a-gun-new-software-will-prevent-it/

Ferenstein, G. 2013. Offshore 3D Printed Gun Blueprint Protector Kim Dotcom Reportedly Deleting Files. Techcrunch. Available at: https://techcrunch.com/2013/05/11/offshore-3d-printed-gun-blueprintprotector-kim-dotcom-reportedly-deleting-files/

Fleschner McMullen, K. 2014. Worlds collide when 3D printers reach the public: Modeling a digital gun control law after the digital millennium copyright act. Michigan State Law Review, 2014(1), 187-225.

Fordyce, R. 2015. Manufacturing Imaginaries: Neo-Nazis, Men's Rights Activists and 3D Printing. Journal of Peer Production Issue 6.

Forzley, M. 2003. Counterfeit Goods and the Public's Health and Safety. Washington DC: International Intellectual Property Institute Report.

Freier, A., 2018. 3D printed sports rifle: Athletics 3D develops Olympic gold-winning rifle with 3D printing. All3DP. Available from: https://all3dp.com/going-for-gold-with-3d-printed-biathlon-sportsrifle/.

Gearty, C. (2007) 'Rethinking Civil Liberties in a Counter-Terrorism World', European Human Rights Law Review (2):111-119.

Gendron, Corinne and Lapointe, Alain and Turcotte, Marie-France, Social Responsibility and the Regulation of the Global Firm (March 15, 2004). Relations Industrielles/Industrial Relations, Vol. 59, No. 1, 2004. Available at SSRN: https://ssrn.com/abstract=1661275; 
Greenberg, A. 2018. A landmark legal shift opens Pandora's Box for DIY guns. WIRED. Available at: https://www.wired.com/story/a-landmark-legal-shift-opens-pandoras-box-for-diy-guns/.

Greenberg, A. 2014. The bullet that could make 3D printed guns practical deadly weapons. WIRED. Available at: https://www.wired.com/2014/11/atlas-314-3-d-printed-guns-bullets/.

Harris Brean, D. 2013. Asserting patents to combat infringement via 3D printing: It's no use. Fordham Intellectual Property, Media \& Entertainment Law Journal, 23(3), 771-814.

Hipolite, W. (2015, May $6^{\text {th }}$ ). Italian police officer 3D prints amazing PCD workstation with articulated arms, 3DPrint.com. Retrieved from: https://3dprint.com/63273/pcb-workstationarticulated/.

Hornick, J. 2017. How police departments are using 3D printing to solve crime. PoliceOne.com. Available at: https://www.policeone.com/police-products/3D-Laser-Scanners/articles/418683006-Howpolice-departments-are-using-3D-printing-to-solve-crime/.

Inagami, Takeshi. "The End of Classic Model of Labor Law and Post-Fordism." Comparative Labor Law and Policy Journal 20.4 (1999): 691-702;

Jacobs J. and Haberman, A. 2017. 3D printed firearms, Do-it-yourself Guns and the Second Amendment. Law and Contemporary Problems, 80(2), 129-147.

Jacobs, S. 2016. The Energy Prosumer. Ecology Law Quarterly. 43, 519.

Jackson, B. 2018. Facebook bans 3D printed guns in news feed, messenger and Instagram. 3D Printing Industry. Available at: https://3dprintingindustry.com/news/facebook-bans-3d-printed-guns-in-newsfeed-messenger-and-instagram-138035/

Jensen-Haxell, P. 2012. 3D Printers, Obsolete Firearm Supply Controls, and The Right To Build SelfDefense Weapons Under Heller. Golden Gate University Law Review, 42(3), 447-495.

Johnson, J.J. 2013. Print, Lock, and Load: 3D printers, creation of guns, and the potential threat to fourth amendment rights. Journal of Law, Technology \& Policy, 2013, 338-361.

Jenzen-Jones, N.R. 2015. Small arms and additive manufacturing: An assessment of 3D-printed firearms, components, and accessories. In B. King and G. McDonald (ed.) Behind the Curve: New Technologies, New Control Challenges. Geneva: Small Arms Survey.

La Pierre, W. 2006. The Global War on your Guns: Inside the UN plan to destroy the Bill of Rights. Nashville: Nelson Current.

Lee, M. 2018. Crime and the Cyber Periphery: Criminological Theory Beyond Time and Space. In K. Carrington, R. Hogg, J.Scott, and M. Sozzo (ed.) The Palgrave Handbook of Criminology and the Global South. Cham, Switzerland: Palgrave Macmillan. 
Legault, Marie-Josée and Bellemare, Guy, Theoretical Issues with New Actors and Emergent Modes of Labour Regulation (December 15, 2008). Relations Industrielles/Industrial Relations, Vol. 63, No. 4, 2008. Available at SSRN: https://ssrn.com/abstract=1596060.

Leung, C. (2017, February $28^{\text {th }}$ ). Hong Kong police to use 3D printers to help make crime scene models, South China Morning Post. Retrieved from: https://www.scmp.com/news/hong-kong/lawcrime/article/2074401/hong-kong-police-use-3d-printers-help-make-crime-scene.

Lewis, A. 2014. The legality of 3D printing: How technology is moving faster than the law. Tulane Journal of Technical and Intellectual Property, 17, 303-318.

Lindstrom, G. 2014. Why should we care about 3D-printing and what are the potential security implications? GCSP Policy Paper 2014/6. Geneva: Geneva Centre for Security Policy.

Lipson, H. and Kurman, M. (2013) Fabricated - The New World of 3D Printing. The promise and peril of a machine that can make (almost) anything. Indianapolis:Wiley.

Little, R.K. 2014. Guns Don't Kill People, 3D Printing Does? Why the Technology is a Distraction from Effective Gun Controls, Hastings Law Journal, 65, 1505-1513.

Mann, M. and Warren, I. 2018. The digital and legal divide: Silk Road, transnational online policing and Southern criminology. In K. Carrington, R. Hogg, J.Scott, and M. Sozzo (ed.) The Palgrave Handbook of Criminology and the Global South. Cham, Switzerland: Palgrave Macmillan.

Mann, M., Warren, I. and Kennedy, S. (2018). The legal geographies of transnational cyberprosecutions: Extradition, human rights and forum shifting. Global Crime, online first, 1-19.

Masero, A.M. 2014. I Came, ITAR, I Conquered: The International Traffic in Arms Regulations, 3DPrinted Firearms, and the First Amendment. Boston College Law Review, 55(4), 1291-1328.

McCutcheon, C.R. 2014. Deeper than a paper cut: Is it possible to regulate three-dimensionally printed weapons or will federal gun laws be obsolete before the ink has dried? University of Illinois Journal of Law, Technology \& Policy, 2014(1), 219-250.

McMullen, K.F. 2014. Worlds collide when 3D printers reach the public: Modeling a digital gun control law after the Digital Millennium Copyright Act. Michigan State Law Review, 2014(1), 187-225.

Mendis, D. and Secchi, D. 2015. A Legal and Empirical Study of 3D Printing Online Platforms and an Analysis of User Behaviour. Project Report. London: Intellectual Property Office.

Mendoza, H. R. (2017, March $7^{\text {th }}$ ). UAE Students Develop 3D Printed Robotic Arms to Aid Stroke Victims and Bomb Disposal Units, 3DPrint.com. Retrieved from: https://3dprint.com/167132/students3d-printed-robotic-arm/. 
Meyer, J. 2013. The basin of the danaides: how 3-D printing will push the limits of international gun control and digital freedom of speech in the twenty-first century. Denver Journal of International Law and Policy, 41(4), 555-573.

Powell, A., Stratton, G. and Cameron, R. 2018. Digital Criminology: Crime Justice in Digital Society. New York: Routledge.

Rayna, T. and Striukova, L. 2016. From rapid prototyping to home fabrication: How 3D printing is changing business model innovation. Technological Forecasting and Social Change, 102, 214-224.

Reeves, P. and Mendis, D. 2015. The Current Status and Impact of 3D Printing Within the Industrial Sector: An Analysis of Six Case Studies. Project Report. London: Intellectual Property Office.

Rifkin, J. 2014. The Zero Marginal Cost Society

Saunders, S. 2018. Justice is served: Abu Dhabi police begin 3D printing initiative to help successfully link evidence to crimes. 3DPrint.com. Available at: https://3dprint.com/209332/abu-dhabi-police-3dprinting/.

Scott, C. (2017, June $8^{\text {th }}$ ). Israeli police unveil first-ever 3D printed police car, 3DPrint.com.

Retrieved from: https://3dprint.com/177289/3d-printed-police-car/.

Shear, M.D., Hsu, T. and Johnson, K. 2018. Judge Blocks Attempt to Post Blueprints for 3-D Guns. The New York Times. Available at: https://www.nytimes.com/2018/07/31/us/politics/3d-guns-trump.html.

Stein, J.A. 2017. The Political Imaginaries of 3D Printing: Prompting Mainstream Awareness of Design and Making. Design and Culture. 9(1): 3-27.

Squires, P. 2019 forthcoming. Semi-automatics for the People? The marketing of a new kind of man. In J. Carlson et al., (ed.) The Routledge Handbook of Firearm Studies. London \& New York: Routledge. Squires, P. 2018. Mr Gingrich's Bequest: Globalising the Second Amendment, in K. Yuill and J. Street (ed.) The Second Amendment and Gun Control: Freedom, Fear, and the American Constitution. London $\&$ New York: Routledge.

Squires, P. 2017. Guns, Crime and Technology in M.R. Maguire and T.J. Holt (ed.) The Routledge Handbook of Technology, Crime and Justice. London \& New York: Routledge.

Squires, P. 2014 Gun Crime in Global Contexts, London \& New York: Routledge.

Tapscott, D. 1997. Digital Economy: Promise and Peril In The Age of Networked Intelligence. New York, McGraw Hill.

Thierer, A.D. and Marcus, A. 2016. Guns, Limbs, and Toys: What Future for 3D Printing? Minnesota Journal of Law, Science and Technology, 17(2), 807-853.

Adam Tickell and Jamie Peck, 'Social regulation after Fordism: regulation theory, neo-liberalism and the global-local nexus' (1995) 24(3) Economy and Society 357 
UNESCO (2018) 'Freedom of expression:A fundamental human right underpinning all civil liberties', https://en.unesco.org/70years/freedom of expression.

Van Brocklin, E. 2015. 'Ghost Gun' Murders and Trafficking Cases Are a Law Enforcement Nightmare Come True. The Trace. Available at: https://www.thetrace.org/2015/10/ghost-gun-lower-receivercalifornia/.

Van Vugt, G. 2013. The Killer Idea: How Some Gunslinging Anarchists Held Freedom of Speech at Gunpoint. In B. van den Berg, S. van der Hof, and C. Mair (eds), eLaw Conference 3D Printing: Destiny, Doom or Dream?, 14-15 November 2013 Leiden, the Netherlands: Centre for Law in the Information Society, 108-29.

Walther, G. 2015. Printing insecurity? The security implications of 3D-printing of weapons. Science Engineering Ethics, 21, 1435-1445. 


\section{Appendix}

Table 1: Instances involving 3D printed firearms and firearm parts

\begin{tabular}{|l|l|l|}
\hline Date & Location & Incident \\
\hline May 2013 & US & $\begin{array}{l}\text { Defense Distributed's Cody Wilson releases design file for } \\
\text { the Liberator which was downloaded more than 100,000 } \\
\text { times worldwide. }\end{array}$ \\
\hline May 2013 & Europe & $\begin{array}{l}\text { Two reporters printed the Liberator and carried it onto a } \\
\text { London to Paris Eurostar train. }\end{array}$ \\
\hline May 2013 & Australia & $\begin{array}{l}\text { NSW Police build and fire two 3D printed firearms. First } \\
\text { gun fired and was confirmed to be lethal. Second gun } \\
\text { exploded. }\end{array}$ \\
\hline July 2013 & Israel & $\begin{array}{l}\text { Journalists 3D print gun, smuggle it into the Israeli } \\
\text { Parliament and point it at the Israeli Prime Minister. }\end{array}$ \\
\hline October 2013 & UK & $\begin{array}{l}\text { 3D printed firearm components located alongside a 3D } \\
\text { printer during a raid on a property in Manchester. }\end{array}$ \\
\hline May 2014 & Japan & $\begin{array}{l}\text { Yoshitomo Imura arrested for possessing 3D printed } \\
\text { firearms and sentenced to two years imprisonment. }\end{array}$ \\
\hline February 2015 & Australia & $\begin{array}{l}\text { Police locate 3D printed firearm parts and individual pleads } \\
\text { guilty to illegal weapons manufacture. }\end{array}$ \\
\hline June 2015 & US & $\begin{array}{l}\text { Police seize AR-15 assault rifle with 3D printed lower } \\
\text { receiver in Oregon. }\end{array}$ \\
\hline May 2016 & Australia & $\begin{array}{l}\text { Police seize a 3D printer used to print firearms in a raid } \\
\text { associated with Outlaw Motorcycle Gangs. }\end{array}$ \\
\hline August 2016 & US & $\begin{array}{l}\text { Transportation Security Administration discover 3D printed } \\
\text { revolver loaded with live ammunition in carry-on luggage at } \\
\text { Reno Airport. }\end{array}$ \\
\hline
\end{tabular}




\begin{tabular}{|l|l|l|}
\hline $\begin{array}{l}\text { November } \\
2016\end{array}$ & Australia & $\begin{array}{l}\text { Police charge five individuals for possession of 3D printed } \\
\text { firearms. Police located four machine guns, weapons } \\
\text { manufacturing equipment, silencers and a 3D printer. }\end{array}$ \\
\hline $\begin{array}{l}\text { December } \\
2016\end{array}$ & Australia & $\begin{array}{l}\text { Police conduct an operation and find 14 firearms. Individual } \\
\text { charged with selling a 3D printed firearm and 3D printed } \\
\text { knuckle dusters. }\end{array}$ \\
\hline March 2017 & Australia & $\begin{array}{l}\text { Individual offered a 3D printed firearm for sale online and } \\
\text { charged with four weapons offences. Police located four } \\
\text { imitation pistols, including two 3D manufactured Glocks, a } \\
\text { 3D-manufactured Sig 250; two air pistols, computer } \\
\text { equipment, and two 3D printers. }\end{array}$ \\
\hline July 2018 & Australia & $\begin{array}{l}\text { Police conduct an operation and find 3D printed handguns } \\
\text { and knuckledusters, false drivers licences and credit cards } \\
\text { and drugs, at a residential property. Individual charged with } \\
12 \text { offences including possessing dangerous weapons, } \\
\text { supplying dangerous drugs and manufacturing a weapon } \\
\text { while not licensed. }\end{array}$ \\
\hline $\begin{array}{l}\text { July- } \\
\text { September } \\
2018\end{array}$ & $\begin{array}{l}\text { US Government and Defense Distributed reach a settlement } \\
\text { regarding DD's distribution of firearms design files, paving } \\
\text { the way for DD to start distributing the files again online; } \\
\text { various state attorney generals successfully obtained an } \\
\text { injunction to prevent the files from being re-distributed via } \\
\text { online download, but DD is currently selling the files to } \\
\text { buyers in certain US states via email and posted USB sticks. }\end{array}$ \\
\hline
\end{tabular}

Table 2: Legal approaches to 3D printed firearms

\begin{tabular}{|l|l|l|}
\hline Country & Law/Policy & Detail \\
\hline UK & Firearms Act 1968 & Prohibits manufacture of firearms and firearm parts. \\
& & $\begin{array}{l}\text { UK Home Office has updated its Guide on Firearms } \\
\text { Licensing Law to mention a ban on 3D printed } \\
\text { weapons. Unlicensed 3D printing of guns is illegal and } \\
\text { punishable by up to 10 years in prison. }\end{array}$ \\
\hline
\end{tabular}




\begin{tabular}{|c|c|c|}
\hline USA & $\begin{array}{l}\text { Undetectable Firearms } \\
\text { Act } 1988 \\
\text { Assembly } \quad \text { Bill } \quad 857 \\
\text { Firearms: Identifying } \\
\text { information } \quad \text { (2016) } \\
\text { (CA) } \\
\text { Regulation of } \\
\text { Individual Conduct } \\
\text { and Activity (2013) } \\
\text { (PA) }\end{array}$ & $\begin{array}{l}\text { Prohibits firearms that cannot be detected by a metal } \\
\text { detector. 3D printed firearms require a metal plate to be } \\
\text { inserted. } \\
\text { California requires a 3D printed gun to be approved and } \\
\text { registered. } \\
\text { Philadelphia has introduced restrictions on the creation } \\
\text { of firearms, or any piece or part thereof, unless a person } \\
\text { possesses a license to manufacture firearms under } \\
\text { federal law. }\end{array}$ \\
\hline Australia & $\begin{array}{l}\text { Firearms and Weapons } \\
\text { Prohibition Legislation } \\
\text { Amendment Act } 2015 \\
(\mathrm{NSW})\end{array}$ & $\begin{array}{l}\text { Introduced new offences in New South Wales relating } \\
\text { to possession of 3D printed firearms and design files. } \\
\text { The first trial of an individual under this legislation is } \\
\text { currently underway at the time of writing. }\end{array}$ \\
\hline China & Trial initiative & $\begin{array}{l}\text { Firms using 3D printing in Chongqing, China are } \\
\text { required to register with authorities in an attempt to } \\
\text { prevent criminal use. Trial could possibly be extended } \\
\text { across China. }\end{array}$ \\
\hline Singapore & Arms and Explosives Act & $\begin{array}{l}\text { Trafficking 3D printed firearm(s) or components } \\
\text { thereof is punishable by the death penalty. The } \\
\text { manufacturing of firearms of components of firearms } \\
\text { using 3D printers without a valid license is prohibited. }\end{array}$ \\
\hline Spain & $\begin{array}{l}\text { Ley Orgánica sobre la } \\
\text { Protección de la } \\
\text { Seguridad Ciudadana } \\
\text { (Law on the Protection } \\
\text { of the Security of the } \\
\text { Citizenry) }\end{array}$ & $\begin{array}{l}\text { Prohibits the dissemination of information (e.g., design } \\
\text { files) related to developing 3D printed firearms } \\
\text { without a valid licence. }\end{array}$ \\
\hline Germany & Weapons Act & $\begin{array}{l}\text { Prohibits the dissemination of information (e.g., design } \\
\text { files) related to developing 3D printed firearms } \\
\text { without a valid licence. }\end{array}$ \\
\hline
\end{tabular}

